\title{
Ethnic Identity from a Macro-Sociological Perspective: Second-generation Iranian "immigrants"
}

\author{
Authors: $\quad$ Fereshteh F. Ahmadi \\ Submitted: $\quad$ 21. February 2017 \\ Published: $\quad$ 22. February 2017 \\ Volume: 4 \\ Issue: 1 \\ Keywords: Racism, Iranians, Second-generation "immigrants", \\ Ethnocentrism, National identity, Ethnic identity \\ DOI: $\quad$ 10.17160/josha.4.1.266
}


Ethnic Identity from a Macro-Sociological Perspective: Second-generation

Iranian "immigrants"

Fereshteh Ahmadi

Professor in Sociology,

Department of Social Work and Psychology

Faculty of Health and Occupational Studies

University of Gävle

80176 Gävle

Mobile +46707171907

Fax: 026-64 8686

Email: faw@hig.se 


\begin{abstract}
:
A feeling of chosenness can result in isolation from other nations and ethnic groups. As it seems, such a feeling of ethnic chosenness may have led to a tendency toward ethnocentrism and in some extreme cases, towards racism found among some Iranians (30\%-40\% according to the world value survey). Such an ethnocentrism may have negative effects on the identity construction of young people, particularly those outside Iran. In the present article, based on studies conducted among IranianSwedish and Iranian-American young people, I will try to shed light on this problem.

Key words: Racism, Iranians, Second-generation "immigrants", Ethnocentrism, National identity, Ethnic identity
\end{abstract}




\section{Introduction:}

David Ali Sonly, the German boy of Iranian heritage who killed 10 people in Munich, seems to have been influenced by the Islamophobia promoted by European extremists, especially by Anders Breivik, a right-wing Christian extremist who killed 77 people in Norway in 2011 in a terror attack targeting multiculturalism.

Some may be surprised that a teenager who himself was from an Iranian immigrant family could have become obsessed with a person like Anders Breivik. Shams (2016) provides the following explanation:

"Some Iranians - particularly in the Diaspora - subscribe to the "Aryan" racial theory promoted by European thinkers in the earlier 20th century. This combines with their dislike for their own government - which too often translates into rabid Islamophobia, as they are unable to distinguish between the actions of the Iranian government and Islam as a whole - to emerge into a disgusting mix of pseudo-scientific racial ideology that sees "Iranians" as "Aryan brothers."

During recent decades, we have seen, both inside and outside Iran, a strengthening of the Persian national and ethnic identity among Iranians. As it seems, such a strengthening has had negative effects on the identity construction of young people, particularly those outside Iran who live in a globalized world, and that such an impact has given rise to an identity crisis among members of this group. In the present article, based on studies conducted among Iranian-Swedish and IranianAmerican young people, I will try to shed light on this problem from a sociological perspective; this by comparing the case of second-generation Iranians in Sweden with that of those in the United States, where the majority of expatriate Iranians 
live. By means of this comparison, I wish to highlight how the following three factors are reflected in the identity building of these young people and create the tensions, among others ethnocentrism, connected with this identity building. These factors are: 1) the impact of the social structure of the societies in which these young people live, 2) the attitudes of Iranian parents toward their cultural and social heritage and, 3) the host population's attitudes toward these young people. My hope is that this cross-society comparison will help in identifying some reasons for the augmentation of ethnocentrism (and in extreme cases racism) among some secondgeneration Iranian immigrants.

\section{Clarification of some concepts}

In the present article, the notion of ethnic identity refers to "Iranian" young people's affiliation with the dominant features of Iranian culture and their sense of belonging to an Iranian minority ethnic group, either in Sweden or in the US. The notion of national identity refers to these young people's affiliation with the dominant features of Swedish (or American) culture and their sense of belonging to Swedish (or American) society. Both of these notions are socially constructed, and the young people's identification involves an ongoing process of negotiation between the culture of their parents and the culture of the country they live in. As Gong (2007: 506) argued:

"The relationship between ethnic identity and national identity can range from negative to no relationship to positive relationship. A negative relationship may be due to feeling of rejection by the society. Lack of a relationship might suggest the perception of the two as non-overlapping. A positive relationship might reflect an integrated bicultural identity. Attitude toward the majority group should be an important factor helping to tease these patterns apart." 
Here, the concept of identity crisis is defined as a tension between two discordant value systems, including the psychological instability such tension may create. In the present discussion, these two value systems are the one adhered to by the parents of second-generation immigrants and the one prevalent in the society these secondgeneration immigrants live in. In the sociological and psychological research, this sense of identity crisis among second-generation immigrants has been well documented. A number of factors have been used to explain it, including the discordance between the cultures of group-oriented societies, from which most migrant groups originate, and the individual-oriented societies they have migrated to (see Oppedal et al. 2004; Berger 1997; Oppedal et al. 2005; Hoerder et al. 2005; Ahmadi Lewin \& Lewin 2003; Ahmadi Lewin 2001; Ahmadi \& Ahmadi 1998). It should be mentioned, that since this article is based on secondary data, no section on the methodology is presented.

\section{Ethnic and national identity among second-generation Iranians}

\section{The Study in Sweden:1}

F. Ahmadi and B. Ahmadi (2012) explored in what way second-generation Iranian immigrants living in Sweden identify with Iranian society, the Iranian ethnic group in Sweden and/or Swedish society. The focus was on the tensions created by these different types of identification. I use the study by F. Ahmadi and B. Ahmadi (2012) to make comparisons between second-generation Iranian immigrants in Sweden and second-generation Iranian immigrants in the US. The data for the Swedish study were collected through e-mail interviews.

\footnotetext{
${ }^{1}$ I have used in this article the result of a study conducted by Babak Ahmadi and me among second-generation Iranian immigrants in Sweden. This result is published in a chapter, "Ethnic identity and the meaning of context: a study of second generation Iranians in Sweden" in a book Iranian Community in Sweden.
} 
Identity: The findings were presented as different patterns. Regarding identification with the Iranian ethnic group in Sweden and/or with Swedish society, four patterns were seen: (1) strong sense of ethnic identity combined with moderate adoption of a Swedish mentality, (2) strong sense of ethnic identity combined with full adoption of a Swedish mentality, (3) moderate ethnic identity combined with full adoption of a Swedish mentality, and (4) low ethnic identity combined with full adoption of a Swedish mentality.

The study showed that all of the interviewees could speak and understand Persian, and that some could also read and write it. The role of ethnicity for the selection of a partner was only important for the group showing Pattern 1, above. All interviewees expressed an interest in Iranian food, but their interest in music, culture, politics, etc., depended on their general involvement and interest in these areas. All interviewees, with the exception of one who reported not having any friends, said they socialized with young people from different ethnic groups and had "a mixture" of friends. Their responses to some questions suggested a tendency toward having a multicultural identity.

The results also indicated that the second-generation Iranian immigrants interviewed were not suffering from any particular identity crisis. However, this does not imply any difference between second-generation Iranian immigrants and so-called "typical Swedish young people." The main perceived difference was the former group's greater dependence on their parents compared with the latter group. This difference has been explained by the fact that the culture in Iran is group oriented, while that in Sweden is individual oriented.

Discrimination: Second-generation immigrants' encounters with society play a considerable role in their approach to ethnic identity. For this reason, the 
interviewees' experiences of and views on discrimination are considered to play a crucial role in how they view their ethnic identity.

The interviewees were asked the following question: "Have you ever felt discriminated against because of your ethnic background? If so, can you briefly describe it?" As regards perceptions of discrimination, four patterns were seen: (1) not discriminated against, (2) not discriminated against (with some reservation), (3) moderately discriminated against, and (4) strongly discriminated against. Each pattern was illustrated using different examples. The principal kind of discrimination was "merit discrimination," meaning that the children of immigrants must have higher merits if they are to compete with the children of Swedes. Unlike their parents, however, the interviewed second-generation Iranian immigrants did not interpret all forms of discrimination as racism.

F. Ahmadi and B. Ahmadi's (2012) study also showed that second-generation Iranians could identify discrimination without pre-judging Swedes and the prevalence of racism among them. It would seem that the second generation distinguishes between racism and discrimination. The interviewees' responses offered no evidence of hostility against Swedes and Swedish society as a result of perceived discrimination.

\section{Comparison with second-generation Iranian immigrants in the US}

One phenomenon in focus, in the literature on second-generation Iranians in the US, is their development of a "reactive identity". According to scholars such as Bozorgmehr and Douglas (2011), this reactive identity has developed in reaction to the American view on Iran, particularly in the aftermath of the events of September 11, 2001: 
"The findings suggested that tense US-Iran relations influenced the way the members of the second generation self-identify. As was the case for Iranian exiles who arrived after the Revolution, the second generation was also likely to assert a Persian identity which deemphasized association with the Islamic Republic of Iran in the post9/11 era, even if 9/11 had nothing to do with Republic of Iran in the post-9/11 era”.

Milani, the author of the book Lost Wisdom (2004), conveyed this reactive identity in the following manner:

"In the anxious wait of such troubled times, the safest path for Iranians was either to become 'invisible' or to opt for the relative safety of a new, hyphenated identity such as Persian-American, or Iranian-American. Such names tried to emphasize, by their very morphology, an emotional detachment from Iran. They posited political distance from the regime at home." (Cited in Vedadi 2007:20)

Growth of such a "reactive identity" has often resulted in idealization of the preIslamic period in Iranian history. Bagheri (2007:80) referred to this as the "Persian myth":

"The Persian Myth is somewhat crippling to Iranian Identity.... These are precisely the heavy layers of historical and cultural identity that many Iranians carry with them, what Fisk describes as the 'malevolent influence of history,' and these heavy layers are often passed on to the next generation." Regarding the idealization of Persian culture among Iranians in the US, Tasuji (2007:5) added: 
"To reconstruct a new national identity for Iranians in America, they have become extremely interested in pre-Islamic Persian civilization. This revived sense of identification for Iranians is based on the hostage crisis and also on the assumption that all Americans have appreciation for pre-Islamic Persian heritage."

Ali Akbar Mehdi, one of the pioneering researchers on this topic in the US, does not believe second-generation Iranians' idealization of pre-Islamic society is solely a reaction to some Americans' negative views on Iran. He also points specifically to the role played by second-generation Iranians' parents and more generally to that of the Iranian community in the US. Mehdi summed up this selective, situational and interpretive approach to Iranian culture using the term "transplanted culture" a culture that has been reconstructed to become more appropriate to the immigrant lifestyle in the host society as well as more consistent with how immigrants view Iranian culture:

"Based on what we know so far about Iranian youths, they are drawing some ideas from the stock of their parental culture. Their references to these cultural objects and symbols are selective, situational, interpretive, and often symbolic. They understand Iranian culture in their own terms, relating to it when suitable and appropriating from it what is relevant to and desirable for them ... This selective and interpretive identification is not unique to these youths; their parents' representation of Iranian culture in the United States also conforms to this pattern. All the observable elements of Iranian culture in Southern California, where the most concentrated and largest Iranian population is located, are indicative of a 'transplanted culture". As a reconstituted reality, these cultural elements are selective, more appropriate 
to the lifestyle of the immigrants in the host society, and consistent with their outlook on Iranian culture.” (1998:77)

There is strong evidence that a "reactive identity" is common, even among secondgeneration Iranian immigrants in Sweden, but this identity does not manifest itself in a return to Iranian culture prior to the Islamic Revolution; instead, it is expressed by stressing one's multicultural and global identity.

How can we explain these differences? Here, I present some reflections on this issue. Many members of the Iranian community in California and Texas (where a large proportion of the Iranian population live) are monarchists, who often overstress their pre-Islamic cultural heritage to justify the Pahlavi regime that preceded the Iranian Revolution (Komaie, 2009). This does not apply in Sweden, where many Iranians belong to the lower middle class, hold left-leaning views and have expressed their opposition to both the former and the existing regime (Hajighasemi 2012).

In Sweden, as in the US and other European countries, the image of Muslim immigrants is negative. However, this negativity is not so strong as to describe young people from Muslim countries, including Iran, as "terrorists." One explanation for the relative weakness of anti-Islamic sentiments in Sweden, compared to those in the US, could be Sweden's egalitarian ideology, as well as its geo-political location.

Unlike in the US, the Iranian community in Sweden is not strong. As the above citations indicate, it is the US Iranian community that, using a different kind of community mass media, has reconstructed Iranian culture, particularly an idealized form of pre-Islamic culture. In Sweden, the Iranian community's relative weakness could be due to the demographics of Iranian immigrants in the country, as well as the lack of a minority-based community tradition. 
The relative weakness of national identity in Sweden and the spread of a multicultural ideology during recent decades, especially among younger people, may be an additional factor. Sweden is one of the few countries to have adopted and attempted to implement multiculturalism as an official policy. Dissemination of a multicultural ideology in Sweden and the ease of movement between European countries may be the principal factors underlying second-generation Iranian immigrants' search for a multicultural and global identity.

Second-generation Iranian immigrants in Sweden have a richer knowledge of the Persian language than their peers in the US do, thus giving the former group a more realistic image of Iranian culture and its diversity. This enhanced knowledge is facilitated by easier travel to $\operatorname{Iran}^{2}$, free access to mother language classes in the Swedish schools and, particularly, the daily use of Persian in the home. In contrast to Iranian parents in Sweden, many Iranian parents in the US do not speak Persian at home. There are two reasons for this: Parents in the US probably mastered English before emigrating from Iran and English has a more positive image internationally.

Although I cannot provide a definite explanation for the observed differences between Sweden and the US, I have presented some reflections that I hope can be used as starting points for understanding: 1) the impact of the social structure of societies in which young "second-generation immigrants" live, 2) the impact of their parents' attitudes toward the Persian cultural and social heritage and 3) the impact of the host population's attitudes toward young second-generation immigrants on their identity building and the tensions related to it.

\footnotetext{
${ }^{2}$ The distance between Sweden (Stockholm) and Iran (Tehran) $3560 \mathrm{~km}$ is much less than USA - especially California- and Iran (Tehran), 10205 km).
} 
Summing up, the comparison has shown (Ahmadi \& Ahmadi 2012) that the identity tension and crisis seen in studies on second-generation Iranian immigrants in the US are not observed among the corresponding generation in Sweden. Naturally, some second-generation Iranian immigrants in Sweden do have a kind of "reactive identity," however, this identity is not manifested in the creation of an "idealized form of Iranian pre-Islamic culture," as it is in the US; instead, in Sweden it is manifested in the formation of a global and multicultural identity.

\section{Discussion:}

Among certain groups of people, ethnic identity can contain notions of "chosenness."

A feeling of chosenness can result in isolation from other nations and ethnic groups. Such chosenness may give rise to attempts to demonstrate that one as belonging to a nation is better than others, for instance by being more highly educated. It is perhaps for this reason that for instance Iranians are very successful as regards their level of educational attainment.

As it seems, such a feeling of ethnic chosenness may have led to a tendency toward ethnocentrism and sometimes racism found among not so few Iranians (30\%-40\% according to the world value survey $)^{3}$. To this we should add another problem, i.e. a strong sense of national identity that is shared not only by those who believe they are from the Aryan race, but also by those with other ethnic backgrounds in Iran, for instance Azeri's (Iranian Turkish speaking minority).

National identity may or may not contain an element of the monolithic. For instance, Americans have a strong national identity without being monolithic, because American society is multicultural and multiethnic. Swedes, however, used to have a "monolithic" national identity, although their society, even before the migration wave into it, was not as monolithic as some believe. Iran is a multicultural country, so we cannot talk about a real

\footnotetext{
${ }^{3}$ http://www.dailymail.co.uk/news/article-2325502/Map-shows-worlds-racist-countries-answerssurprise-you.html
} 
monolithic national identity among Iranians. Instead, what creates a sense of monolithic national identity among Iranians is, like the Greeks, their shared historical memory - a memory of the glory of the past civilization and its high culture.

The combination of a strong sense of a monolithic national identity and a sense of ethnic identity that relies on the notion of chosenness brings about isolation from other ethnic groups and a sense of superiority among some second-generation Iranian immigrants, which has led to the intensification of ethnocentrism in this group. The problem of ethnocentrism becomes more serious if we take into consideration the problem of identity crisis in this group.

As I have tried to show, the construction of a glorious past, a cultural heritage that stands as an alternative to the humiliating present situation (of being considered an enemy and immigrant), has brought about an identity crisis among IranianAmerican young people. We can consider the same phenomena among young people with an Iranian heritage in some European societies. Although F. Ahmadi and B. Ahmadi (2012) did not observe any serious signs of identity crisis among second-generation Iranians in Sweden, given the increase in racism in Europe as well as Sweden, this problem could also develop in this and other immigrant groups. If the ideology of "Aryan" racial theory is applied by some Iranians, inside and outside Iran, this could strongly intensify the problem and give rise to isolation of young second-generation Iranians from young people with other ethnic backgrounds. If young second-generation Iranians find themselves in a situation of not being accepted by the host society, then this crisis could lead to the serious consequences.

As Alex Shams (2016) mentions, adopting a mix of pseudo-scientific racial ideology that sees "Iranians" as "Aryan brothers" is "fundamentally an attempt by 
Iranians in the Diaspora assimilate, to distinguish themselves from other immigrants by claiming to be as close to Europe and Whiteness as possible."

In conclusion, I should mention that the problem is not merely Iranians' racial attitudes or young immigrants' identity crisis. According to Kenan Malik (2016), what defines our time's young jihadists' or young racists' violence is not always legitimate or political anger, but often a sense of personal anger. As Malik sees it, today the boundaries between ideological violence, pent-up aggression and some type of antisocial personality seem to have been more or less dissolved. He emphasizes that, in the past, the difference between political violence and sociopathic rage was relatively clear. This is no longer the case. This is partly because the ideological foundations of violence have been so watered down, and partly because aggression has become an increasingly common feature of public life. One reason is that the moral and social boundaries that have traditionally functioned as a firewall against that kind of behavior have broken down. In recent years, Western societies have become both more socially divided and more fragmented by identity politics. According to Malik, the influence of institutions that once contributed to people's socialization and that gave them a sense of responsibility to each other, from churches to unions, has weakened. As people's more broadly defined identities have eroded, the authority of traditional social networks and institutions has been undermined, and people's sense of belonging has become increasingly narrow. Malik correctly maintains that progressive movements that resulted in sociopolitical bottling have weakened. New oppositional movements are often based on religious or ethnic affiliation, and are sectarian or separatist in nature. There is growing alienation and contempt for what is considered "mainstream," as well as a mounting feeling that the world is out of control or controlled by malevolent forces. Overall, these developments have 
contributed to a feeling of rage that has no outlet - a feeling that undermines people's sense of responsibility to each other as living beings and dissolves the boundary between sociopathy and violence. 


\section{References}

- Ahmadi Lewin, F. \& Lewin, B. (2003). Sexualitet och heder: Identitet i kris hos unga människor med utländsk bakgrund. In N. Ahmadi (Ed.) Ungdom, kulturmöte, identitet (Youth-hood, Cultural Encounter, identity). (pp.139-158). Stockholm: Liber AB.

- Ahmadi Lewin, F. (2001). Identity Crisis and Integration. The divergent Attitudes of Iranian Immigrant Men and women towards Integration into Swedish society. International Migration 39(3), 121-135.

- Ahmadi, F. \& Ahmadi, B. (2012). Ethnic identity and the meaning of context: a study of second generation Iranians in Sweden. In H. Hosseini-Kaladjahi (Ed.). The Iranian Community in Sweden. (pp. 193-220). Stockholm: Almqvist \& Wiksell International.

- Ahmadi, N. \& Ahmadi, F. (1998). Iranian Islam; The Concept of the Individual. New York: MacMillan Press.

- Bagheri, A. (2007). Iranian-American Identities: Peeling Away the Layers. In T. Wilcox-Ghanoonparvar (Ed.). Hyphenated Identities: Second-Generation Iranian-Americans Speak. (pp. 72-81). Costa Mesa: California Mazda Publishers.

- Berger, R. (1997). Adolescent Immigrants in Search of Identity: Clingers, Eradicators, Vacillators and Integrators. Child and Adolescent Social Work Journal, 14, 263-275. Published online.: doi:10.1023/A:1024594308783

- Bozorgmehr, M. \& Douglas, D. (2011). Success(ion): Second-Generation Iranian Americans. Iranian Studies, 44(1), 3-24. 
- Gong, L. (2007). Ethnic identity and identification with the majority group: Relations with national identity and self-esteem. International Journal of Intercultural Relations, 31, 503-523.

- Hajighasemi, A. (2012). The political life of Iranian immigrants in Sweden. In H. Hosseini-Kaladjahi (Ed.). The Iranian Community in Sweden. (pp. 65-93). Stockholm: Almqvist \& Wiksell Intrnational.

- Hoerder D., Hebert Y. \& Schmitt I. (2005). Negotiating Transcultural Lives: Belongings and Social Capital among Youth in Comparative Perspective. Torento: University of Toronto Press.

- Komaie, G. (2009). The Persian veil: Ethnic and racial self-identification among the adult children of Iranian immigrants in Southern California. University of California, Irvine.

- Malik, K. (2016). Ilskans terrorism har ersatt det politiska våldet (Anger terrorism has replaced political violence). Svenska Dagbladet. http://www.svd.se/ilskans-terrorism-har-ersatt-det-politiska-valdet.

- Mehdi, A. A. (1998). Ethnic Identity among Second-Generation Iranians in the United States. Iranian Studies, 31(19), 77-95.

- Milani, A. (2004). Lost Wisdom: Rethinking Modernity in Iran. Washington: Mage Publishers

- Oppedal B., Røysamb E. \& Heyerdahl S. (2005). Ethnic group, acculturation, and psychiatric problems in young immigrants. Journal of Child Psychology and Psychiatry, 45(6), 561-672.

- Oppedal B., Røysamb E. \& Lackland S. D. (2004). The effect of acculturation and social support on change in mental health among young immigrants. International Journal of Behavioral Development, 28(6), 481-494. 
- Shams, A. (2016). Why Did the Munich Killer Beg Us to See Him as German? http://www.huffingtonpost.com/alex-shams/why-did-the-munich$\underline{\text { killer_b_11154486.html }}$

Tasuji, N. 2007. Reconstructing a New Identity. In T. Wilcox-Ghanoonparvar (Ed.). Hyphenated Identities: Second-Generation Iranian-Americans Speak. (pp.1-9). Costa Mesa: California Mazda Publishers.

- Vedadi, N. And Iran, Iran's So Far Away. In T. Wilcox-Ghanoonparvar (Ed.). Hyphenated Identities: Second-Generation Iranian-Americans Speak. (pp.1026). Costa Mesa: California Mazda Publishers

- Wilcox-Ghanoonparvar T. (2007). Hyphenated Identities: Second-Generation Iranian-Americans Speak. Costa Mesa: California Mazda Publishers.

- Zhou, M. (1997). Growing up among Americans: The Challenge Confronting Immigrant Children and Children of Immigrants. Annual Review of Sociology, 23, 63-95. 


\section{Short biography:}

Fereshteh Ahmadi, PhD, full Professor of Sociology, Faculty of Health and Occupational Studies, University of Gävle, Sweden. Professor Ahmadi is presently specializing in issues related to identity, health, religion and spirituality. In addition, she has conducted research on gerontology, international migration, Islamic Feminism and Music and coping at Uppsala University. She is responsible for an international project on Meaning-Making Coping. The project involves researchers from Sweden, South Korea, China, Japan and Turkey. Ahmadi is the author of 52 books and articles. 